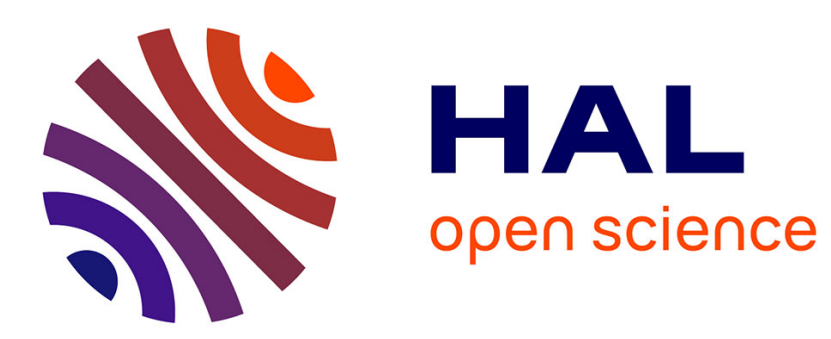

\title{
Crowdsourcing of Accessibility Attributes on Sidewalk-Based Geodatabase
}

\author{
Michaela Riganova, Jan Balata, Zdenek Mikovec
}

\section{To cite this version:}

Michaela Riganova, Jan Balata, Zdenek Mikovec. Crowdsourcing of Accessibility Attributes on Sidewalk-Based Geodatabase. 16th IFIP Conference on Human-Computer Interaction (INTERACT), Sep 2017, Bombay, India. pp.436-440, 10.1007/978-3-319-68059-0_46 . hal-01679789

\section{HAL Id: hal-01679789 \\ https://hal.inria.fr/hal-01679789}

Submitted on 10 Jan 2018

HAL is a multi-disciplinary open access archive for the deposit and dissemination of scientific research documents, whether they are published or not. The documents may come from teaching and research institutions in France or abroad, or from public or private research centers.
L'archive ouverte pluridisciplinaire HAL, est destinée au dépôt et à la diffusion de documents scientifiques de niveau recherche, publiés ou non, émanant des établissements d'enseignement et de recherche français ou étrangers, des laboratoires publics ou privés.

\section{(c)(1)}

Distributed under a Creative Commons Attribution| 4.0 International License 


\title{
Crowdsourcing of Accessibility Attributes on Sidewalk-based Geodatabase
}

\author{
Michaela Riganova, Jan Balata, and Zdenek Mikovec \\ Faculty of Electrical Engineering, \\ Czech Technical University in Prague, Czech Republic
}

\begin{abstract}
Although the issue of limited mobility affects a large portion of the population, current navigation systems working with roadwaybased geodatabases are designed primarily for cars and therefore cannot efficiently help. Usage of the professionally created sidewalk-based geodatabase is a solution. However, the professional geographical "on-site reconnaissance" is labor demanding. In this poster, we report on results of preliminary research focused on a design of the gamified collection of accessibility attributes by non-expert crowd, which will reduce the data collection cost. Preliminary results suggest the feasibility of the approach supported by a proper guidance of non-experts and creativity of achieving precise measurements.
\end{abstract}

\section{Introduction}

According to Sammer et al. [9], almost $16 \%$ of the population is limited in mobility, namely visually impaired, hearing impaired, wheelchair users, and people with impaired ability to walk. Appropriate navigation system considering sidewalks and their accessibility attributes can help significantly. However, current navigation systems are created for cars, thus ignoring sidewalks, crosswalks, landmark information and important accessibility attributes.

To address this issue, we designed a sidewalk-based geodatabase ${ }^{1}$ (Geographical Information System - GIS) with the following features: line features tied to large part of the pedestrian segment (a sidewalk, a crosswalk, an underpass) with attributes (sidewalk slope, material, light signalization, traffic noise); point features tied to short part of the pedestrian segment that acts as a barrier (a staircase, obstacle) or a landmark (corner, recess) with attributes (corner shape, number of steps, unobstructed width).

The GIS is created in two phases: 1) Pedestrian segments with line and point features are drawn into the GIS by a professional using resources such as satellite imaging, a "map of town utilities," creating a template for the second phase. 2) The template is filled in with attributes assigned to the features via professional "on-site reconnaissance," which is highly labor demanding. The features and their attributes were carefully designed and selected in cooperation with orientation and mobility specialists. The GIS enabled us, for example, to generate landmark-enhanced itineraries for blind pedestrians [1].

\footnotetext{
${ }^{1}$ Route4All - http://www.route4all.eu/en/
} 
Our aim is to design a mobile application for collection of pedestrian attributes of segment features in the field using crowdsourcing. The non-experts will fill the data in the professionally created template of the GIS for a fraction of the effort of professional "on-site reconnaissance." The research questions are: How to accommodate the expert language to be well understood by non-experts? What methods will non-experts use for measurements? How to efficiently visualize pedestrian segments on a map? What is the quality of non-expert collected geodata? What is the efficiency of introduced gamification elements?

\section{Related Work}

Recently, there were attempts to improve sidewalk accessibility using Google Street View: a collection of crossroads data [3] and public transport stations locations [5] to be described to visually impaired people, or barriers on sidewalks and crosswalks [6] to hint wheelchair users about accessibility. However, neither used the data in sidewalk-based GIS to enable efficient routing and route description.

Comparing the quality of crowdsourced geodata from experts and non-experts, See et al. [10] conclude that it do not differ significantly and non-experts can improve using training or examples (especially concerning accessibility where they are not as proficient [11]). Moreover, the crowd can not only provide the data, but also provide their validation [2]. Regarding motivation of the crowd, Mooney and Corcoran [8] conclude that majority of geodata is often contributed by the minority of users. On the other hand, crowdsourcing geodata that brings benefit to the community of contributors can be used as a motivation [7]. The gamification proved to be a good motivation for crowdsourcing, using concepts like points, leaderboards, etc. [4].

\section{Crowdsourcing of Accessibility Attributes}

In our research, we consider following scenarios of crowdsourcing: 1) collecting new attributes for the features like sidewalk slope and material, corner shape, crosswalk curbs, ramps and signalization, 2) reporting temporary obstacles like potholes or construction works, 3 ) crowd validation of the crowdsourced geodata.

\subsection{Design process and preliminary results}

The expert language is often complex and not well understood by non-experts. To observe relevant non-expert language conventions for attributes description and their skills when collecting accessibility geodata without any special equipment, we organized three focus group sessions with 11 participants of various age (22$26,27-35,35-51)$.

Each group received a simplified hand-drawn map of pedestrian segments with line and point features of our interest (see Fig. 1a). The tasks were to 


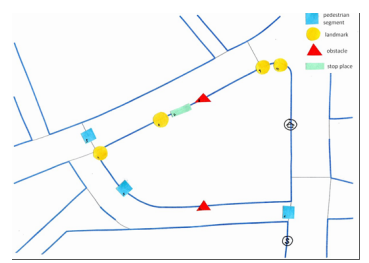

a)
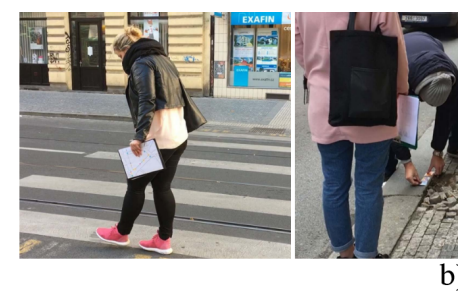

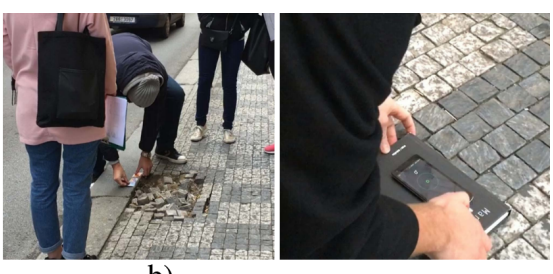

b)

Fig. 1. a) A map representing template of the GIS - shapes depict features for which the attributes were collected; b) examples of measuring methods used.

name depicted features and collect data about their accessibility attributes. We were interested mainly in the shapes of corners, properties of crosswalks (such as a presence of tactile pavement, audio signalization, a presence of ramp or curb), positions of obstacles, passable widths, slopes and materials of pedestrian segments and properties of tram stops.

All participants were able to agree on a single term for given features. On the other hand, the participants struggled to name some of their attributes (e.g., the shape of a corner, different kinds of a slope, type of tactile paving surfaces). Regarding the slope, in the end, participants agreed on "direct slope" for longitudinal slope and "side slope" for cross slope.

The participants were not provided with any special tools for measuring required attributes. For measuring length, width, and depth, the most common technique was stepping or using their feet. They also used credit cards and squared paper as compensation for a meter (see Fig. 1b). However, the participants struggled to measure an exact slope of pedestrian segments; they even tried using a mobile app. However, it was not sensitive enough. Instead, they used terms as "gentle," "small," "smooth" or "slightly" uphill/downhill.

Based on the results from focus groups, we designed pictograms in combination with easy-to-understand language for the description of pedestrian segment features and their attributes. We conducted 4 design probe sessions based on paper mock-ups concluding that most participants do not want to spend too much time collecting the geodata and they proposed faster methods of input such as sliders, drop-down menus, or drag\&drop instead of text fields for precise values. Further, they doubted clarity of pictograms for complicated attributes such as a presence of guiding lines for visually impaired on crosswalks and they mentioned that they would prefer additional photo example.

\subsection{Gamification elements}

Further, we elaborated on suitable gamification elements to engage crowdsourcing activities. Based on [4], we selected weekly and overall leaderboards, badges, weekly missions - where the task is to collect accessibility attributes for a particular combination of features, and credibility - based on validation of user's crowdsourced data by other users. Moreover, we introduced personalizations such 

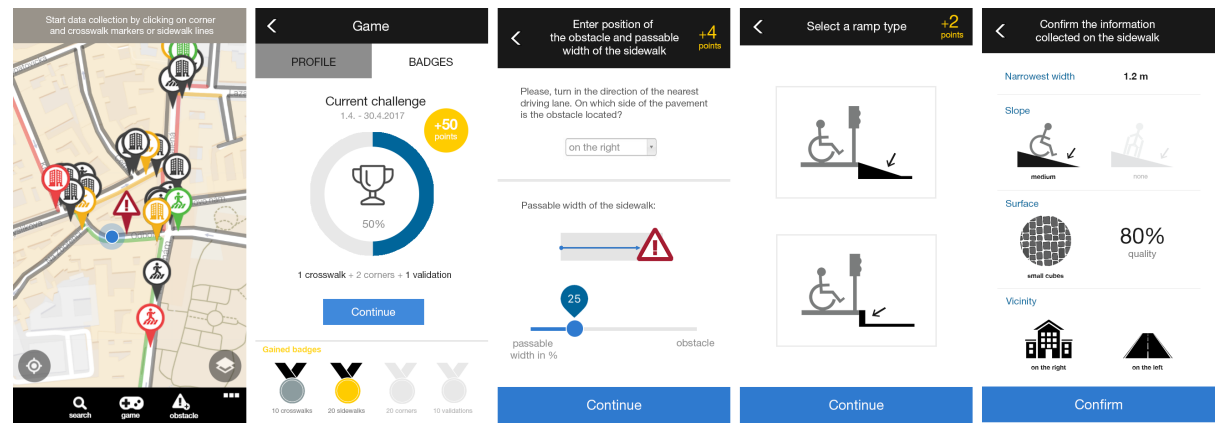

Fig. 2. From the left: a pedestrian segment visualization with features; gamification elements; obstacle reporting; crosswalk ramps; recapitulation of collected data.

as profile photo and nickname. These gamification elements were later included in a further design process.

\subsection{Next steps}

Currently, we are creating a hi-fi prototype using HTML and JavaScript. The main challenges are a visualization of the pedestrian segments, features and attributes over Google Maps on a mobile device; and how to support the identification of the desired features or reported obstacles by non-expert users (see Fig. 2). After the usability inspection of the hi-fi prototype, we plan to conduct a long-term experiment evaluating the quality of collected accessibility attributes and efficiency of gamification elements.

\section{Conclusion}

We present first design steps of the application for crowdsourced collection of pedestrian accessibility attributes in the urban environment. Focus group sessions were directed at accommodation of the expert language to non-expert users and the methods they can use for attributes measurement. Created paper mockup was evaluated in design probes. In the future, we aim to compare the quality of the collected data by non-experts and efficiency of gamification elements.

Acknowledgements The research has been supported by the project Navigation of handicapped people funded by grant no. SGS16/236/OHK3/3T/13 (FIS 161 - 1611663C000) and by Czech Radio Foundation project "Světluška".

\section{References}

1. Balata, J., Mikovec, Z., Bures, P., Mulickova, E.: Automatically generated landmark-enhanced navigation instructions for blind pedestrians. In: Computer 
Science and Information Systems (FedCSIS), 2016 Federated Conference on. pp. 1605-1612. IEEE (2016)

2. Goodchild, M.F., Li, L.: Assuring the quality of volunteered geographic information. Spatial statistics 1, 110-120 (2012)

3. Guy, R., Truong, K.: Crossingguard: exploring information content in navigation aids for visually impaired pedestrians. In: Proceedings of the SIGCHI Conference on Human Factors in Computing Systems. pp. 405-414. ACM (2012)

4. Hamari, J., Koivisto, J., Sarsa, H.: Does gamification work?-a literature review of empirical studies on gamification. In: System Sciences (HICSS), 2014 47th Hawaii International Conference on. pp. 3025-3034. IEEE (2014)

5. Hara, K., Azenkot, S., Campbell, M., Bennett, C.L., Le, V., Pannella, S., Moore, R., Minckler, K., Ng, R.H., Froehlich, J.E.: Improving public transit accessibility for blind riders by crowdsourcing bus stop landmark locations with google street view: An extended analysis. ACM Transactions on Accessible Computing (TACCESS) $6(2), 5(2015)$

6. Hara, K., Le, V., Froehlich, J.: Combining crowdsourcing and google street view to identify street-level accessibility problems. In: Proceedings of the SIGCHI conference on human factors in computing systems. pp. 631-640. ACM (2013)

7. Klettner, S., Huang, H., Schmidt, M., Gartner, G., Buchroithner, M., Prechtel, N., Burghardt, D.: Acquisition and cartographic applications of subjective geodata. In: Cartography from Pole to Pole: Selected Contributions to the XXVIth International Conference of the ICA, Dresden 2013 (2014)

8. Mooney, P., Corcoran, P.: Characteristics of heavily edited objects in openstreetmap. Future Internet 4(1), 285-305 (2012)

9. Sammer, G., Uhlmann, T., Unbehaun, W., Millonig, A., Mandl, B., Dangschat, J., Mayr, R.: Identification of mobility-impaired persons and analysis of their travel behavior and needs. Transportation Research Record: Journal of the Transportation Research Board (2320), 46-54 (2012)

10. See, L., Comber, A., Salk, C., Fritz, S., van der Velde, M., Perger, C., Schill, C., McCallum, I., Kraxner, F., Obersteiner, M.: Comparing the quality of crowdsourced data contributed by expert and non-experts. PloS one 8(7), e69958 (2013)

11. Zeng, L., Kühn, R., Weber, G.: Improvement in environmental accessibility via volunteered geographic information: a case study. Universal Access in the Information Society pp. 1-11 (2016) 